\title{
УДК 616.381-002-031.81
}

\section{ПАТОГЕНЕТИЧЕСКИЕ АСПЕКТЫ РАЗВИТИЯ ПАРЕЗА КИШЕЧНИКА ПРИ ПЕРИТОНИТЕ}

\author{
Чернядьев С. А., Булаева Э. И., Кубасов К. А. \\ ФГБОУ ВО «Уральский государственный медицинский университет» Минздрава России, г. Екатеринбург, Россия
}

\section{Резюме}

Перитонит является частым осложнением в абдоминальной хирургии и характеризуется высокой летальностью. Синдром кишечной недостаточности является одним из ключевых факторов прогрессирования распространенного перитонита. Самым характерным и самым ранним проявлением синдрома кишечной недостаточности является развитие моторно-эвакуаторной дисфункции кишечника. Развитие интестинального пареза обеспечивается каскадом нервно-рефлекторных и гуморальных реакций организма с развитием выраженных микроциркуляторных нарушений и метаболических сдвигов. Формирование энтеральной недостаточности обусловлено развитием внутрикишечной и абдоминальной компрессии, гипоксическим повреждением слизистой оболочки кишки на стадии всасывательно-переваривающей дисфункции кишечника. Развивающаяся бактериальная транслокация индуцирует развитие и прогрессирование синдрома полиорганной дисфункции и обусловливает выраженность эндогенной интоксикации. Угнетение всех функций кишечника приводит к так называемой «энтераргии»- универсальной энтеральной недостаточности.

Ключевые слова: парез кишечника, перитонит, синдром кишечной недостаточности.

\section{PATHOGENETIC ASPECTS OF THE DEVELOPMENT OF INTESTINAL PARESIS IN PERITONITIS}

\section{Chernjadev S.A., Bulaeva E.I., Kubasov K.A.}

Ural State Medical University, Yekaterinburg, Russian Federation

\section{The summary}

Peritonitis is a frequent complication in abdominal surgery and is characterized by high mortality. Intestinal insufficiency syndrome is one of the key factors in the progression of peritonitis. The development of motorevacuation dysfunction of the intestine is the most typical and the earliest manifestation of the syndrome of intestinal insufficiency. The cascade of neuro-reflex and humoral reactions of the organism with the development of pronounced microcirculatory disturbances and metabolic changes provide the development of intestinal paresis. The development of internal intestinal and abdominal compression, hypoxic damage of the intestinal mucosa induce the formation of enteric insufficiency at the stage of absorptive-digestive bowel dysfunction. Bacterial translocation starts and induces the progression of multiorgan failure syndrome and determines the severity of endogenous intoxication. The oppression of all the functions of the intestine leads to the so-called «enterargia» - a universal enteral insufficiency.

Keywords: intestinal paresis, peritonitis, syndrome of intestinal insufficiency.

\author{
Адрес для переписки: \\ Булаева Элина Ильдаровна \\ ФГБОУ ВО «УГМУ» Минздрава России \\ 620028, Екатеринбург, Репина, д. 3 \\ Тел.: 8(922) 1420620 \\ E-mail: iriss@mail.ru
}

\author{
Correspondence address: \\ Bulaeva Elina Ildarovna \\ Ural State Medical University, the Russian Federation \\ 620028, Yekaterinburg, Repin Str., 3, \\ Phone: +7(922) 1420620 \\ E-mail: iriss@mail.ru
}

\author{
Образец цитирования: \\ Чернядьев С. А., Булаева Э. И., Кубасов К.А. \\ "Патогенетические аспекты развития пареза китечника \\ при перитоните» \\ Проблемы стоматологии, 2016, Т. 12, № 4. С. 84-89 \\ doi: 10.18481/2077-7566-2016-12-4-84-89 \\ (C) Чернядвев C. A. и соавт., 2016
}

\author{
For citation: \\ Chernjadev S.A., Bulaeva E. I., Kubasov K.A. \\ «Pathogenetic aspects of the development of intestinal \\ paresis in peritonitis» \\ The actual problems in dentistry, \\ 2016. Vol. 12, № 34, pp. 84-89 \\ DOI: 10.18481/2077-7566-2016-12-4-84-89
}


Одним из наиболее частых и опасных осложнений в абдоминальной хирургии является распространенный перитонит. Летальность при данном заболевании не имеет тенденции к снижению и, по данным различных авторов, колеблется от 15 до 60\%, а при послеоперационном перитоните достигает 80-90\% и более. Сепсис развивается в 41,7-78,3\% случаев острого перитонита, при этом летальность, обусловленная развитием полиорганной недостаточности, возрастает до $60 \%$ и более. При нарушении функции двух органов летальность составляет 30-40\%, а четырех и более 90-100\%. При развитии гнойно-септического процесса происходит запуск каскада процессов универсальной стресс-реакции $[3,4,7,13,14]$.

Первой «мишенью» распространенного перитонита является кишечный тракт, что проявляется нарушением сократительной способности желудка и кишечника либо расстройством ее координации, приводя к развитию или усугубляя многие патологические процессы, часто определяя тяжесть состояния пациента и исход заболевания $[5,8,16]$.

В патогенезе перитонита одним из ключевых факторов прогрессирования заболевания является синдром кишечной (энтеральной) недостаточности $[1,10]$. Формирование энтеральной недостаточности обусловлено развитием внутрикишечной и абдоминальной компрессии, гипоксическим повреждением слизистой оболочки, способствующим транслокации бактерий и усилению эндогенной интоксикации, являющейся причиной смерти более $30 \%$ больных [13, 15]. Выраженность синдрома энтеральной недостаточности пропорциональна тяжести перитонита [12].

Синдром кишечной недостаточности это нарушение пищеварительно-транспортных и барьерных функций кишечника при острой хирургической патологии и травмах брюшной полости, вследствие чего кишечник становится основным источником интоксикации и главной причиной абдоминального сепсиса, осложняющего течение послеоперационного периода у 30-50\% пациентов после ликвидации причины перитонита, устранения или отграничения источника инфицирования, тщательной санации брюшной полости даже в условиях массивной антибактериальной терапии [8].

В течении синдрома кишечной недостаточности выделяют 3 стадии:
1 стадия - моторно-эвакуаторная дисфункция - угнетение моторики кишечника без нарушения всасывания;

2 стадия - всасывательно-переваривающая дисфункция - резкое нарушение всасывания жидкости, газов; растяжение кишки; венозный стаз; размножение микрофлоры с колонизацией проксимальных участков;

3 стадия - универсальная энтеральная недостаточность - нарушение микроциркуляции и отек стенки кишки; транслокация токсинов и микробов в кровь, лимфу, брюшную полость; метаболические расстройства $[8,11]$.

В 1986 г. американскими исследователями Дж. Меакинс и Дж. Маршалл впервые была выдвинута гипотеза развития полиорганной недостаточности в результате изменения проницаемости слизистой оболочки кишечника и транслокации бактерий и токсинов в систему циркуляции. Также этими авторами были высказаны два очень образных мнения: «Кишечник - двигатель полиорганной недостаточности» (1986) и «Кишечник - недренированный абсцесс полиорганной недостаточности» (1993) [7].

Пищеварительный тракт в настоящее время рассматривается как физиологический, механический и иммунологический барьер. Патологические нарушения, развивающиеся в тонкой кишке, являются зоной повышенного внимания ученых ввиду большой площади и существенного влияния на обменные процессы в организме $[11,18]$.

Согласно экспериментальным данным первая стадия СКН развивается через 6 часов после моделирования перитонита, вторая через 12 часов, а третья стадия формируется через 24 часа после опыта. В клинической же практике время развития каждой из его стадий определить практически невозможно, так как синдром кишечной недостаточности формируется задолго до поступления пациента с острой хирургической патологией в клинику. Наиболее часто больные поступают на 2-3 стадии синдрома кишечной недостаточности, которые даже при оперативном пособии трудноразличимы. Однако установлено, что самым характерным и наиболее ранним клиническим проявлением синдрома энтеральной недостаточности является нарушение моторики кишечника, вне зависимости от того, была ли нарушена целостность кишечной трубки или нет [9]. 
Альтерация при перитоните приводит к раздражению обширного рецепторного поля брюшины и к тормозному нервно-рефлекторному воздействию по типу висцеро-висцеральных рефлексов, провоцируя нарушение моторики тонкой кишки. Процесс развития моторно-эвакуаторной дисфункции кишечника рассматривается как компенсаторно-адаптационная реакция организма, целью которой является снижение бактериальной контаминации и отграничение воспалительного процесса в брюшной полости.

На стадии моторно-эвакуаторной дисфункции в кишечной стенке еще не наступают микроциркуляторные нарушения, нет существенного снижения всасывания пищевых веществ и нет накопления газов и жидкости в просвете кишки. Это позволяет моторике кишечника самостоятельно восстанавливаться при условии устранения патологического процесса без нарастания тяжести эндогенной интоксикации [11].

Проведение вегетативными нервами тормозной импульсации при перитоните непосредственно к гладкой мускулатуре кишечника и гладкомышечным клеткам кровеносных сосудов сопровождается усилением тонуса симпатического и угнетением парасимпатического отделов вегетативной нервной системы. Следом запускается нарушение гуморальных механизмов регуляции, заключающееся в выбросе катехоламинов, активации калликреин-кининовой системы с избыточным поступлением в кровоток гистамина, брадикинина, протеолитических ферментов, снижением биологической активности клеток APUD-системы - серотонина (субстанции Р) и мотилина, стимулирующих работу мигрирующего миоэлектрического комплекса кишки, дисрегуляторном поступлении секретина, холецистокинина и энтероглюкагона. Возрастающая концентрация в крови биологически активных веществ запускает деполяризацию мембран гладкомышечных волокон кишечной стенки с последующей их трансминерализацией. Активация калликреин-кининовой системы, избыточное накопление биологически активных веществ подавляют перистальтическую активность кишечника за счет угнетения функции энтерорецепторов и водителей ритма сокращения [11].

Симоненков А.П. выдвинул теорию о роли серотонина и серотониновых рецепторов в генезе дисфункции гладкой мускулатуры, являющейся составной частью клинического синдрома серотониновой недостаточности. В настоящее время доказана роль серотонина в регуляции функций желудочно-кишечного тракта. Более $95 \%$ из всех запасов серотонина лоцируется в желудочно-кишечном тракте [10].

Основным коллектором серотонина являются энтерохроматофинные клетки эпителия кишечных крипт, где он синтезируется из L-триптофана и аккумулируется в секреторных гранулах. Кроме того, серотонин активно накапливается в серотонинергических нейронах тонкокишечной нервной системы.

Серотонин, в ответ на химическое или механическое раздражение, воздействует на перистальтику и кишечный транспорт электролитов, действуя как медиатор межнейрональных связей в гладкомышечной оболочке тонкой кишки. После активации серотонинового каскада нейроны тонкокишечной нервной системы выпускают другие медиаторы, регулирующие перистальтику кишечника. Также серотонин активирует внешние сенсорные нейроны, обеспечивающие физическое восприятие от кишечника, такие как ощущение тошноты, метеоризма и боли.

Нарушение взаимодействия серотонина с серотониновыми рецепторами гладкомышечной ткани лежит в основе дисфункции гладкой мускулатуры. Развитие перитонита приводит к нарушению синтеза серотонина, вызывая серотониновую недостаточность и, как следствие, гладкомышечную недостаточность. Достоверно выявлено снижение уровня эндогенного серотонина в 2,5 раза среди больных с перитонитом, в сравнении с нормой [10].

Синдром кишечной недостаточности на 2-й стадии характеризуется растяжением кишечных петель и повышением внутриполостного давления, ввиду выраженных метаболических сдвигов и внутриклеточных электролитных нарушений [9]. Эфферентная импульсация, поступающая из энтерорецепторов пораженной брюшины и брыжейки, не только угнетает двигательную функцию тонкой кишки, но и вызывает уменьшение объемного кровотока в мезентериальном бассейне и нарушение микроциркуляции в кишечной стенке [11]. Согласно серотониновой концепции, происходит нарушение взаимодействия серотонина со специфичными ему рецепторами, что ведет к нарушению эндогенной вазомоторики и микроциркуляции. Такие изменения приводят к локальной 
и регионарной гипоксии, повреждению и некрозу тканей, вызывая дисфункцию гладкой мускулатуры [10].

Микроциркуляторные и вазомоторные нарушения в виде снижения интрамурального кровотока ведут к местному повышению венозного давления, угнетению резорбции газов и дальнейшему увеличению внутрикишечного давления. Если внутрикишечное давление достигает уровня диастолического давления, прекращается всасывание жидкости, приводящее к еще более выраженному растяжению тонкой кишки и нарушению трофики кишечной стенки $[10,11]$.

При развитии энтеральной недостаточности при перитоните изменяется состав основных мембранообразующих фракций липидов и увеличение доли свободных жирных кислот и лизофосфолипидов, что характеризуется мембранодестабилизирующими явлениями в тканях кишечника. В этом процессе важную роль играют гипоксия и процессы перекисного окисления липидов. Как известно, метаболические нарушения, характеризующие 3-ю стадию синдрома кишечной недостаточности, стартуют в слизистой оболочке, распространяясь по мере прогрессирования заболевания и на серозномышечный слой кишечной стенки [15].

Замедление или прекращение пассажа кишечного содержимого приводит к резкому изменению микрофлоры кишечника в сторону роста численности условно-патогенных микроорганизмов (аллохтонной микрофлоры), преимущественно грамотрицательных, активно продуцирующих экзо- и эндотоксин. Распространение толстокишечных микроорганизмов в верхние отделы желудочно-кишечного тракта с активизацией процессов брожения и гниения и образованием избыточного количества высокотоксичных веществ характеризует процесс «бактериальной транслокации» [2, 9, 10, 17].

Патологическая флора желудочно-кишечного тракта при длительном парезе становится дополнительным источником эндогенной интоксикации бактериального происхождения и полиорганного инфицирования за счет эндотоксиновой агрессии и эндотоксинемии. В таких условиях снижается барьерная функция слизистой оболочки кишки, угнетается функциональная активность лимфатической и ретикулоэндотелиальной систем. При нарушении барьерной функции кишечника на 3-й стадии синдрома кишечной недостаточности происходит транслокация флоры и токсинов из просвета кишечной трубки в брюшную полость, лимфатическое русло, портальный и системный кровоток. При синдроме кишечной недостаточности и распространенном перитоните желудочно-кишечный тракт является исходным (первичным) и потенциальным (вторичным) источником эндогенной интоксикации, а толстая кишка - «мотором» полиорганной недостаточности $[8,9,10]$.

Содержание освобождаемого в результате гибели грамотрицательных бактерий эндотоксина, метаболическая интоксикация, нарушение мезентериального кровообращения и степень пареза кишечника прямо пропорциональны интенсивности портальной и системной эндотоксинемии [9].

В исследовании Костырного А. В. и соавт. также подтверждается прямая корреляционная зависимость степени пареза желудка и кишечника и выраженности эндогенной интоксикации у больных при разлитом перитоните [5].

В настоящее время бактериальная транслокация признана ведущим звеном насыщения организма эндотоксином (с включением липополисахаридного комплекса) - основным индуктором развития синдрома системного воспалительного ответа, абдоминального сепсиса и полиорганной недостаточности. Характер и выраженность эндогенной интоксикации, развитие и прогрессирование синдрома полиорганной дисфункции непосредственно связаны с интенсивностью бактериальной транслокации [10].

Снижение интрамурального кровотока сопровождается резким снижением интенсивности процессов переваривания и всасывания, прекращается эвакуация содержимого. Активные процессы брожения и гниения, симбионтного пищеварения приводят к ускорению накопления жидкости и газов в просвете кишки [11]. Паретическая дилатация кишечника вызывает усиление секреции желудка и кишечника. Ввиду механического сдавления микроциркуляторного русла и затруднения венозного оттока, повышения проницаемости сосудов появляется воспалительный отек кишечной стенки, вызывающий транссудацию жидкости в просвет кишки. Эти процессы способствуют растяжению петель тонкой кишки и повышению внутриполостного давления, усугубляя микроциркуляторные нарушения и приводя к гипоксии кишечной стенки 
с формированием стойкого пареза. При этом артериальное кровоснабжение кишечной стенки значимо не снижается [11].

Эндогенные и экзогенные токсины, микробные тела и продукты катаболизма воздействуют на кишечную стенку, приводя к высвобождению большого количества кислых гидролаз, промежуточных продуктов незавершенного метаболизма (альдегидов, этанола, скатола, кадаверина, сероводорода, индола, аммиака, свободного фенола и др.), повреждающих тканевую структуру тонкой кишки. Воздействуя на самое уязвимое звено - нейроны мышечного сплетения, токсические продукты приводят к нарушению холинергической иннервации кишечника и передачи нервных импульсов. Присоединяющаяся гипоксия кишечной стенки приводит к глубоким нарушениям клеточного метаболизма, гибели нейронов интрамурального нервного аппарата, патологическим изменениям в мышечной оболочке кишечника вплоть до коагуляционного и колликвационного некроза миоцитов [11].

Угнетение всех функций кишечника (моторной, эвакуаторной, переваривающей, всасывательной), вызванное деструктивными процессами в брюшной полости, приводит к так называемой «энтераргии» - универсальной энтеральной недостаточности.

Большие объемы жидкости, поступающие в просвет кишки, повышают внутрибрюшное давление и вызывают расстройство обмена веществ, что приводит к нарастанию интоксикации и нарушениям гомеостаза. Заключительный этап заболевания характеризует быстрый рост метаболических расстройств: значительная некомпенсированная потеря белка, воды и солей, электролитов, дегидратация тканей и азотемии, развитие метаболического ацидоза и т. д.

Таким образом, одним из ведущих механизмов в патогенезе перитонита признано развитие синдрома кишечной недостаточности: от ранних функциональных расстройств до последующего органического повреждения кишечника. Транслокация кишечной флоры может быть первичным или вторичным механизмом развития системного воспалительного ответа и сепсиса и важным звеном в развитии полиорганной недостаточности [11].

\section{Литература}

1. Абу Варда Фатхи Хадер. Энтеральный путь коррекции синдрома кишечной недостаточности в хирургической тактике лечения больных с ургентной абдоминальной патологией: автореф. дис. ... канд. мед. наук / Абу Варда Фатхи Хадер. - Рязань, 2012.

2. Бредикис, Ю.Ю. Использование методов электрической стимуляции органов в клинической практике / Ю. Ю. Бредикис // Материалы 1-го съезда Всесоюзного научно-медикотехнического общества: тез. докл. - Москва, 1975. - Ч. 1- С. 31-35.

3. О значении электрической стимуляции в лечении послеоперационных парезов кишечника / А. А. Вишневский, Г.Д. Вилявин, А.В. Лившиц [и др.] // Функциональная непроходимость пищеварительного тракта. - Москва, 1967. - С. 424-427.

4. Калинина, Л.И. Электростимуляция при заболеваниях пищеварительного тракта / Л.И. Калинина, А. Ф. Агеев, О.С. Кочнев // Мат. I Всесоюзной научной конференции «Электрическая стимуляция органов и тканей». - Каунас, 1975. - С. 183-185.

5. Оптимизация диагностики и контроль лечения пареза желудка и кишечника в раннем послеоперационном периоде при разлитом перитоните / А. В. Костырной [и др.] // Клінічнахірургія. - 2013. - № 6. - С. 29-32.

6. Интенсивная терапия больных с тяжелым абдоминальным сепсисом и полиорганной недостаточностью / А. Л. Левит, О. Г. Малкова, Ф.В. Галимзянов, С. В. Крашенинников [и др.] // Уральский медицинский журнал. 2007. - № 10. - С. 29-32.

7. Паршин, Д. С. Лечение синдрома кишечной недостаточности у больных с разлитым перитонитом / Д. С. Паршин, М.А. Топчиев // Вестник Тамбовского университета. Серия: Естественные и технические науки. - 2013. - Т. 18, № 1. - C. 296-298.

8. Критерии выбора эффективной тактики хирургического лечения распространенного перитонита / В. С. Савельев [и др.] // Анналы хирургии. - 2013. - № 2. - С. 48-54.

9. Савельев, В.С. Перитонит и эндотоксиновая агрессия / В. С. Савельев, В.А. Петухов. - Москва: Медицина, $2012 .-326$ с.

10. Соловьев, И.А. Послеоперационный парез кишечника - проблема абдоминальной хирургии / И.А. Соловьев, А. В. Колунов // Вестник Национального медико-хирургического Центра им. Н. И. Пирогова. - 2013. - Т. 8, № 2. C. $112-118$.

11. Суковатых, Б.С. Механизмы развития распространенного перитонита / Б.С. Суковатых, Ю.Ю. Блинков, О. Г. Фролова // Вестник экспериментальной и клинической хирургии. - 2012. - Т. 2. - С. 469-477. 
12. Особенности течения синдрома энтеральной недостаточности у пациентов с распространенным перитонитом / Х. Д. Таха, А. Е. Аллниази, А. К. Ахманов, А. С. Инютин // Казанский мед. ж. - 2015. - Т. 96, № 4. - С. 489-492. DOI:10.17750/KMJ2015-489.

13. К вопросу диагностики ранних признаков полиорганной дисфункции у больных с синдромом энтеральной недостаточности / А. В. Федосеев [и др.] // Перитонит. - 2012. - Т. 3, № 1. - С. 24.

14. Чернядьев, С. А. Особенности распространения и динамика острого панкреатита в современных условиях / С. А. Чернядьев, Н.Г. Шестков // Российский медико-биологический вестник им. академика И.П. Павлова. 2008. - №4. - С. 64-68.

15. Патогенетические основы энтеральной недостаточности / В. А. Шибитов, Т. И. Власова, Э. И. Полозова, П. А. Власов [и др.] // Фундаментальные исследования. - 2012. - №4-1. - С. 152-156.

\section{References}

1. Abu Varda Fathi Hader. Enteral path of correction of intestinal insufficiency syndrome in the surgical treatment tactics for patients with urgent abdominal pathology: avtoref. dis... cand. med. sciences / Abu VardaFathi Hader - Rjazan, 2012. - 26p.

2. Bredikis, Ju. Ju. The use of methods of electrical stimulation of organs in clinical practice / Ju. Ju. Bredikis // Materialy 1-go sezdaVsesojuznogonauchno-medikotehnicheskogoobshhestva: Tez. dokl. - Moscow, 1975. - Vol. 1- P. 31-35.

3. Vishnevskij, A.A. About the importance of electrical stimulation in the treatment of postoperative paresis of the intestine / A.A. Vishnevskij, G. D. Viljavin, A. V. Livshicetc // Functional obstruction of the digestive tract. - Moscow, 1967. - P. $424-427$.

4. Kalinina, L. I. Electrical stimulation in diseases of the digestive tract / L. I. Kalinina, A. F. Ageev, O. S. Kochnev // Mat. I Vsesojuznoj nauchnoj konferencii «Jelektricheskaja stimuljacija organov I tkanej». - Каунас, 1975. - P. 183-185.

5. Kostyrnoj, A. V. Optimization of diagnostics and monitoring of treatment of paresis of the stomach and intestine in the early postoperative period when diffuse peritonitis / A. V. Kostyrnoj // Klinichna hirurgija. - 2013. - № 6. - P. 29-32.

6. Intensive care patients with severe abdominal sepsis and multiple organ failure / A. L. Levit, O. G. Malkova, F. V. Galimzyanov, S. V. Krasheninnikov [et al.] // Ural medical journal. - 2007. - № 10. - P. 29-32.

7. Parshin, D. S. Treatment of intestinal insufficiency syndrome in patients with spilled peritonitis / D. S. Parshin, M.A. Topchiev // Vestnik Tambovskogo universiteta. Serija: Estestvennye I tehnicheskie nauki. - 2013. - Vol. 18, № 1. - P. $296-298$.

8. Savelev, V. S. Selection criteria of effective tactics of surgical treatment of widespread peritonitis / V. S. Savelev // Annaly hirurgii. - 2013. - № 2. - P. 48-54.

9. Savelev, V.S. Peritonitis and endotoxin aggression / V. S. Savelev, V.A. Petuhov // Moscow: Medicina. - 2012. - 326p.

10. Solovev, I. A. Postoperative paresis of the intestine - the problem is abdominal surgery / I. A. Solovev, A. V. Kolunov // Vestnik Nacionalnogo mediko-hirurgicheskogo Centra im. N. I. Pirogova. - 2013. - Vol. 8, № 2. - P. 112-118.

11. Sukovatyh, B. S. Mechanisms of development ofwidespread peritonitis / B. S. Sukovatyh, Ju. Ju. Blinkov, O. G. Frolova // Vestnik jeksperimental'noj I klinicheskoj hirurgii. - 2012. - Vol. 2. - P. 469-477.

12. Peculiarities of syndrome of enteral insufficiency at patients with diffuse peritonitis / H.D. Taha, A.E. Allniazi, A. K. Ahmanov, A. S. Injutin // Kazanskij med. zh. - 2015. - Vol. 96, №4. - P. 489-492 . - DOI:10.17750/KMJ2015-489.

13. Fedoseev, A. V. To the question of the diagnosis of the early signs of multiple organ dysfunction in patients with syndrome of enteral insufficiency / A. V. Fedoseev // Peritonitis. - 2012. - Vol. 3, № 1. - P. 24.

14. Chernyadev, S.A. Distribution features and dynamics of acute pancreatitis in modern conditions / S.A. Chernyadev, N. G. Hearths // Russian medico-biological Bulletin them. academician I. P. Pavlov. - 2008. - №4. - P. 64-68.

15. Pathogenetic bases of enteral insufficiency / V.A. Shibitov, T.I. Vlasova, Je. I. Polozova, P. A. Vlasov [et al.] // Fundamentalnye issledovanija. - 2012. - №4-1. - P. 152-156

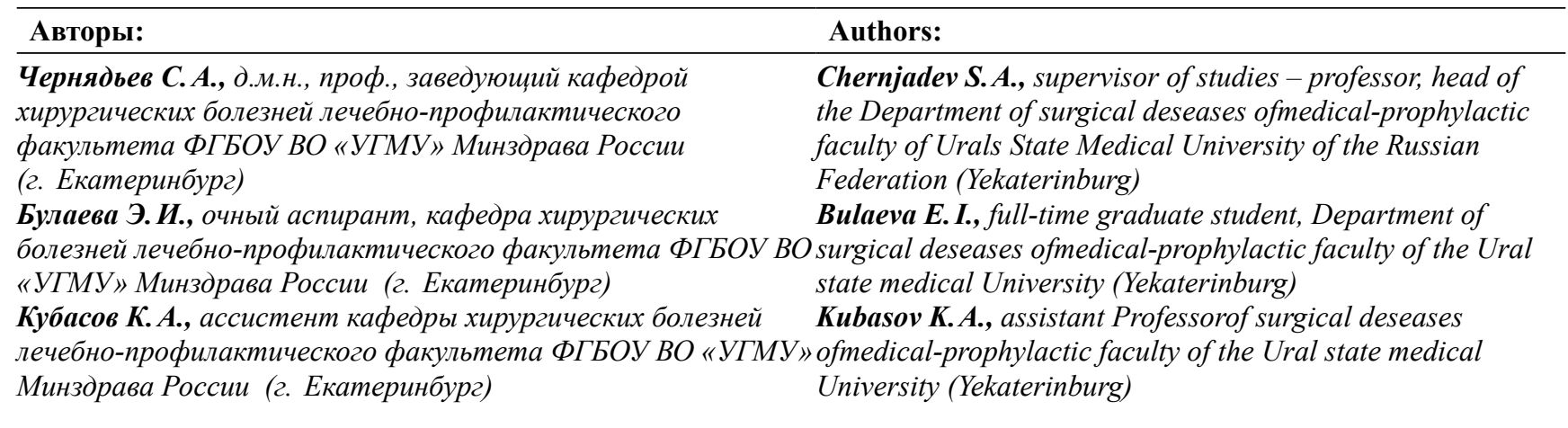

Поступила 29.10.2016

Принята к печати 03.11.2016
Received 29.10.2016

Accepted 03.11.2016 